»Ein Gefühl von freierem Leben«

Deutsche Dichter in Italien 


\title{
»Ein Gefühl von freierem Leben«
}

\author{
Deutsche Dichter in Italien
}

\author{
von \\ Gunter E. Grimm, Ursula Breymayer \\ und Walter Erhart
}

J.B. Metzlersche Verlagsbuchhandlung

Stuttgart 
CIP-Titelaufnahme der Deutschen Bibliothek

Grimm, Gunter:

»Ein Gefühl von freierem Leben« : deutsche Dichter in Italien /

von Gunter E. Grimm ; Ursula Breymayer u. Walter Erhart. -

Stuttgart : Metzler, 1990

ISBN 978-3-476-00710-0

NE: Breymayer, Ursula:; Erhart, Walter:

ISBN 978-3-476-00710-0

ISBN 978-3-476-03322-2 (eBook)

DOI 10.1007/978-3-476-03322-2

Dieses Werk einschließlich aller seiner Teile ist urheberrechtlich geschützt.

Jede Verwertung außerhalb der engen Grenzen des Urheberrechtsgesetzes ist ohne

Zustimmung des Verlages unzulässig und strafbar. Das gilt insbesondere für Vervielfältigungen, Übersetzungen, Mikroverfilmungen und die Einspeicherung und Verarbeitung in elektronischen Systemen.

(C) 1990 Springer-Verlag GmbH Deutschland

Ursprünglich erschienen bei J.B. Metzlersche Verlagsbuchhandlung und Carl Ernst Poeschel Verlag GmbH in Stuttgart 1990 


\section{Inhalt}

Einführung: Die Italiensehnsucht der Deutschen Seite 1

\section{$I$. \\ Vom Pilgerzug zum Kunsterlebnis}

Zwischen Erdenjammer und Kunstgenuß. Pilger, Gelehrte und Kavaliere auf Reisen Seite 17

»Ich sehne mich herzlich wieder nach Deutschland « - Lessing, der mißgelaunte Italienreisende Seite 34

»Ein unaufhörliches Vergnügen«. Wilhelm Heinses dionysischer

Italienzug Seite 42

\section{II.}

Goethe und seine Zeitgenossen

» ̈̈ther ohne Wolken ...«Mythos und Wirklichkeit in Goethes italienischen

Metamorphosen Seite 57

»Ich bin nicht Goethe.« Johann Gottfried Herders italienische

Bedrängnisse Seite 93

Mit den Augen eines Außenseiters: Johann Gottfried Seume und die Entdeckung der italienischen Wirklichkeit Seite 102

»Von Reu' zur Gier, von Gier zur Reu’«. Zacharias Werners römisches

»Damaskus« Seite 112

III.

\section{Die Verlegenheit der Epigonen}

»In Schutt liegt eure Größe« - Grillparzers kritische Italienvisite Seite 125

»Wer die Schönheit angeschaut ... « August von Platens Flucht aus

Deutschland Seite 136

Weltschmerz und Emanzipation. Heinrich Heines Attacken gegen die »Bildungsphilister« Seite 156

»Stellt euch Hamburg in Trümmern vor und ihr habt Pompeji«. Hebbel, Scheffel, Fontane - die distanzierten Beobachter Seite 172 
IV.

»Strahlend und fatal«: Schönheitsfeier im Fin de Siècle

»Gott ist tot« - »Es lebe der Gott Italiens«. Friedrich Nietzsches Metaphysik des Südens Seite 189

»Es regt sich ein Heimweh nach Märchenpracht ...«. Venedig-Impressionen um

1900 und in der Dichtung Hugo von Hofmannsthals Seite 206

Dichterfürst und Taugenichts. Die Italienreisen Gerhart Hauptmanns und Hermann Hesses Seite 219

V.

Lust und Last des Erbes. Deutsch-italienische Begegnungen im 20. Jahrhundert

»Laterna-magica-Bilder«. Italien als Ort der deutschen >Inneren Emigration< Seite 241

Neorealismus und magische Momente. Alfred Anderschs literarische Italienporträts Seite 259

Ewige Streiterei mit dem ewigen Rom: Marie Luise Kaschnitz Seite 273

Entzauberung eines Mythos? Zum Italienbild deutscher

Gegenwartsliteratur Seite 283

Anhang:

Anmerkungen Seite 303

Editorische Notiz Seite 337

Ortsregister Seite 339

Namensregister Seite 342

Verzeichnis der Abbildungen Seite 347 
"Reisen, die Erde und ihre Geschöpfe kennen lernen, ist die natürliche Bestimmung des Menschen: Stille sitzen und Phantasieen schmieden, sein unnatürlicher Zustand«.

Wilhelm Heinse, Tagebuch vom 9. August 1783

»Das ist das Angenehme auf Reisen, daß auch das Gewöhnliche durch Neuheit und Überraschung das Ansehen eines Abenteuers gewinnt."

Goethe, Italienische Reise, 9. März 1787 